\title{
Removal of Silica and Alumina as Impurities from Low-Grade Iron Ore Using Wet High-Intensity Magnetic Separation and Reverse Flotation
}

\author{
Kazutoshi Haga*, Moses Charles Siame, Atsushi Shibayama \\ Graduate School of International Resource Science, Akita University, Akita, Japan \\ Email: *khaga@gipc.akita-u.ac.jp
}

How to cite this paper: Haga, K., Siame, M.C. and Shibayama, A. (2018) Removal of Silica and Alumina as Impurities from Low-Grade Iron Ore Using Wet HighIntensity Magnetic Separation and Reverse Flotation. Journal of Minerals and Materials Characterization and Engineering, 6, 382-394.

https://doi.org/10.4236/jmmce.2018.63027

Received: April 23, 2018

Accepted: May 18, 2018

Published: May 21, 2018

Copyright $\odot 2018$ by authors and Scientific Research Publishing Inc. This work is licensed under the Creative Commons Attribution International License (CC BY 4.0).

http://creativecommons.org/licenses/by/4.0/

\begin{abstract}
This study investigates the removal of silica and alumina as impurities from hematite based low-grade iron ore containing 34.18 mass\% iron, 31.10 mass\% of silica and 7.65 mass\% alumina. Wet high-intensity magnetic separation (WHIMS) and reverse flotation (RF) were investigated. In WHIMS process, $93.08 \%$ of iron was recovered with a grade of 53.22 mass\% at an optimum magnetic density of $10,000 \mathrm{mT}$, and pulp density of $2 \%$ used the L-4 machine. In RF experiments, optimal results showed $95.95 \%$ of iron recovered with 51.64 mass\% grade using $1 \mathrm{~kg} / \mathrm{t}$ of $1 \%$ alkaline starch as iron depressant and $1: 1$ mixture ratio of $0.75 \mathrm{~kg} / \mathrm{t} \mathrm{DAA}$ and $\mathrm{NaOL}$ as silica and alumina collectors. The designed multi-stage process involving feeding the concentrate from WHIMS into RF process reduced silica to 2.02 mass\%, alumina to 1.04 mass $\%$ whilst recovering $81.94 \%$ of the iron with 67.27 mass\% grade. As a result of this research, a process to produce high quality iron concentrate from hematite based low-grade iron ore with high iron recovery rate was constructed.
\end{abstract}

\section{Keywords}

Iron Ore, Hematite, Magnetic Separation, Reverse Floatation, Multi-Stage Process

\section{Introduction}

The increase in demand for iron in the steelmaking industries and the depleting high-grade iron ores has led to the alternative extraction of iron from hematite based low-grade ores [1]. The low-grade iron ores contain higher grades of silica 
and alumina as gangue mineral assemblages with oxides of phosphorus existing in small quantities [2]. In this study, Sanje ore of Nampundwe area of Zambia containing 31.10 mass\% grade of iron and more than 38 mass\% silica-alumina gangue minerals as impurities was used. The ore contains high alumina and silica and it is to be used as feed in steelmaking; however these impurities adversely affect the production of pig iron and steel [3]. High silica and alumina also form high viscous slag with greater volume in blast furnaces which requires more flux [4]. Therefore, these impurities need to be removed before feed into the steel making process.

Magnetic separation and flotation are the two commonly used iron beneficiation processes and selecting the most effective process to treat low-grade ore depends mainly on the mineralogical structure of the ore especially the aggregation of Iron with gangue minerals [5]. Magnetic separation using wet high-intensity technique has become one of the most suitable methods for recovery of iron from low-grade ores [6], due to its better separation efficiency as compared to dry magnetic separation and gravity separation [7]. Flotation processes using either cationic or anionic collectors are therefore considered as the more most effective methods to separate iron-gauge minerals which are aggregated together and are weak magnetic particles [8]. Many studies on reverse magnetic flotation put across performances comparison between anionic and cationic collectors in terms of iron recovery and gangue separation efficiencies. In many cases, anionic collectors have lower recovery efficiencies due to poor selectivity while cationic exhibits low efficiency due to high viscosity and low foam mobility [9]. Cationic reverse flotation is usually $\mathrm{pH}$ dependent process and is done effectively at lower $\mathrm{pH}$ range from $\mathrm{pH} 9$ to 10 as compared to anionic flotation which is done for $\mathrm{pH}$ range from $\mathrm{pH} 11$ to $\mathrm{pH} 12$ (Ana et al., 2017) [10]. However, even with these technologies, it could not build a capable process of collecting high grade iron concentrate with high iron recovery from hematite-based ores.

This research aimed at designing a process to produce iron concentrate with minimal silica-alumina content of less than 7 mass $\%$ and higher iron grade of more than 60 mass\% to meet both market requirement and production target. Wet high-intensity magnetic separation (WHIMS) was investigated; however it could not completely remove the silica-alumina gangue particles entrapped and aggregated with iron particles. Reverse flotation using cationic, anionic collectors and their combination also were investigated. The multi-stage separation processes were designed and compared and the best process with less metal loss for impurity removal was established based on experimental results.

\section{Experiment}

\subsection{Sample Preparation}

The sample was prepared by crushing the ore to $2 \mathrm{~mm}$ using the P-1 Jaw crusher (Fritsch Co, Ltd.) and milling $200 \mu \mathrm{m}$ using P-13 disc mill (Fritsch Co, Ltd.). Chemical composition analysis for the milled samples was done using X-ray flu- 
orescence spectrometer (XRF, ZSX Primus II Rigaku). Table 1 shows that the ore also contains silica and alumina of 31.10 mass $\%$ and 7.65 mass\% respectively. Mineralogical analysis was done using RINT Rigaku X-ray diffractometer as results shown in Figure 1. The ore contains hematite $\left(\mathrm{Fe}_{2} \mathrm{O}_{3}\right)$, silica $\left(\mathrm{SiO}_{2}\right)$ and small amount of magnetite $\left(\mathrm{Fe}_{3} \mathrm{O}_{4}\right)$.

\subsection{Procedure for Magnetic Separation}

All magnetic separation experiments were done using the Series L Model 4 (L-4 Machine) laboratory magnetic Separator (Eriez Magnetics Co. Ltd.). Wire mesh (expand metal) or pipe matrix fixed inside the casing of L-4 machine were used as magnetic particle collectors. The effect of magnetic flux density on silica and alumina removal was first investigated by adjusting for 3000, 5000, 7500 and $10,000 \mathrm{mT}$ while pulp density and pulp flow were kept constant at $2 \%$ and 7 $\mathrm{L} / \mathrm{min}$ respectively. The value of the magnetic flux density indicates the value obtained by measuring the magnetic flux density at the center of the collection box filled with the matrix. The effect of feed pulp density on iron recovery investigated by adjusting the density of slurry fed into the machine to $2 \%, 2.5 \%, 5 \%$, $7.5 \%$ and $10 \%$ at the optimum magnetic field intensity obtained from the first stage while keeping the pulp flow of $7 \mathrm{~L} / \mathrm{min}$.

Table 1. Chemical composition of Sanje Iron ore (analysed by XRF).

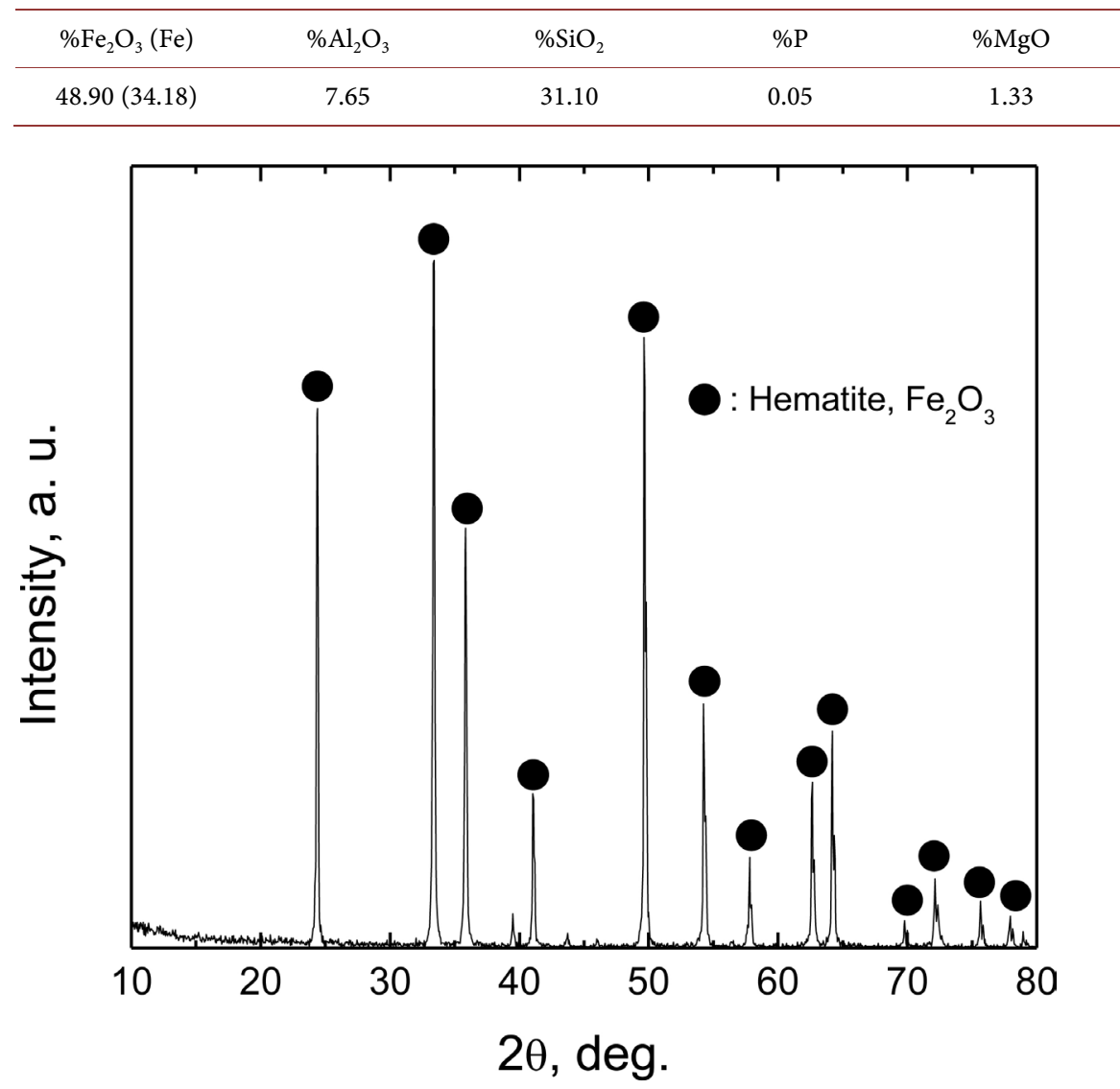

Figure 1. XRD pattern for Sanje Iron ore. 


\subsection{Procedure for Reverse Flotation}

Flotation experiments were carried out using 237 FL flotation machine (Mekhar-Tekhnika Corp.) with $500 \mathrm{~mL}$ capacity, mixing at $900 \mathrm{rpm}$ and 0.5 $\mathrm{L} / \mathrm{min}$ of air injected. The effect of $\mathrm{pH}$, collector dosage, iron depressant (starch) dosage were studied to establish best flotation parameters. $0.1 \%$ of sodium oleate $(\mathrm{NaOL})$ was used as an anionic collector and $0.1 \%$ dodecyl amine acetate (DAA) as a cationic collector. Alkaline starch prepared by $1 \%$ starch $\left(\mathrm{C}_{18} \mathrm{H}_{32} \mathrm{O}_{16}\right)$ and $0.1 \%$ sodium hydroxide solution mixed to 1:1 molar ratio was used as an iron depressant and methyl isobutyl carbinol (MIBC) was used as frother.

\section{Results and Discussion}

\subsection{Magnetic Separation}

\subsubsection{Effect of Magnetic Density}

The effect of magnetic density on iron recovery and gangue removal was investigated at constant pulp flow using the expand metal as magnetic collector in Figure 2. Recovery of iron and its grade increased with increase in magnetic intensity. Evidently, iron recovery improved from $76 \%$ to $93 \%$ with an increase in magnetic field density from $3000 \mathrm{mT}$ to $10,000 \mathrm{mT}$. Silica content in the concentrate was reduced to 18.79 mass $\%$ at $10,000 \mathrm{mT}$ as compared to 19.98 mass\% at $3000 \mathrm{mT}$. Increase in the magnetic field beyond $10,000 \mathrm{mT}$ resulted in decreased recovery due to the buildup of magnetic particles on matrix [6] [11].

\subsubsection{Effect of Feed Pulp Density}

Figure 3 shows that recovery of iron decreased from $93 \%$ to $91 \%$ for pulp density of $2 \%$ to $2.5 \%$ at constant magnetic field density of $10,000 \mathrm{mT}$. Further increase in pulp density caused a relatively decreasing trend in iron recovery and lower silica-alumina gangue removal. The optimum pulp density was obtained at

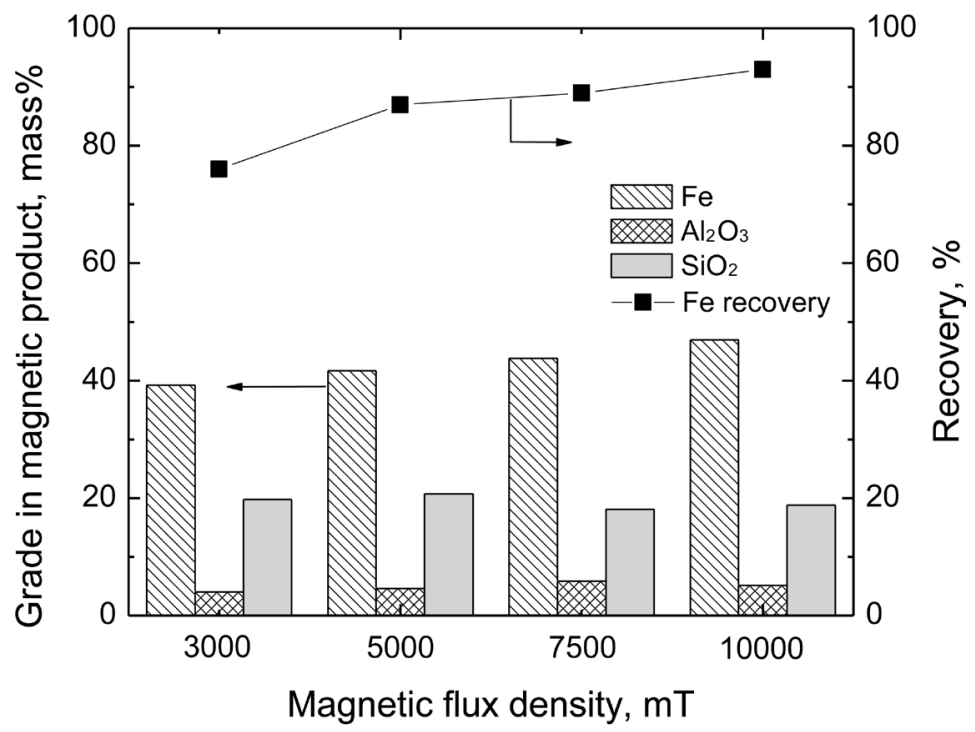

Figure 2. Changing of iron recovery and grade as a function of magnetic density on WHIMS (Conditions: pulp density $2 \%$, pulp flow rate $7 \mathrm{~L} / \mathrm{min}$, matrix expand metal). 
$2.5 \%$ at which $89 \%$ of iron was recovered with the grade of 49.72 mass $\%$ having 4.19 mass\% alumina and 18.08 mass\% of silica. At $2.5 \%$ the solid-liquid ratio at which the magnetic forces dominated over the liquid drag force. Lower pulp density increased pulp flow reduced the probability at which the particles were induced and captured by the matrix. Alternatively, higher pulp flow caused overcrowding on the matrix and reduced separation efficiency [12] [13].

\subsubsection{Effect of Matrix}

Figure 4 shows effect of matrix equipment on recovery and grade. The optimum magnetic field density of $10,000 \mathrm{mT}$ and feed pulp $2.5 \%$ was used to investigate

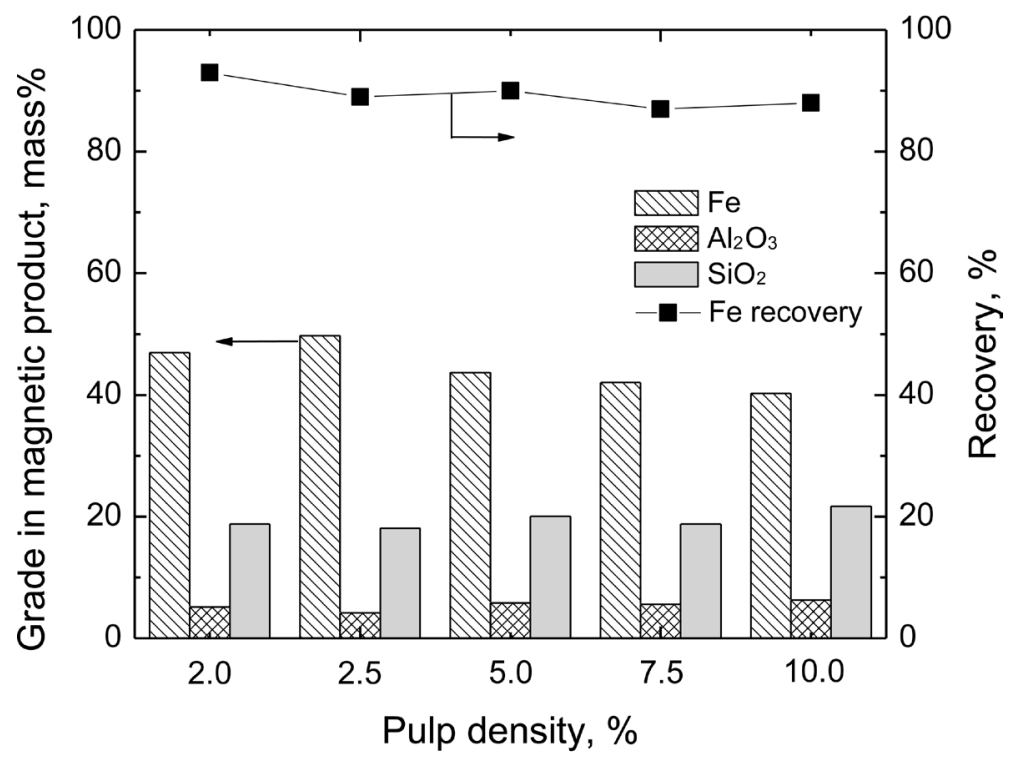

Figure 3. Changing of iron recovery and grade as a function of pulp density on WHIMS (conditions: magnetic density 10,000 $\mathrm{mT}$, pulp flow rate $7 \mathrm{~L} / \mathrm{min}$, matrix expand metal).

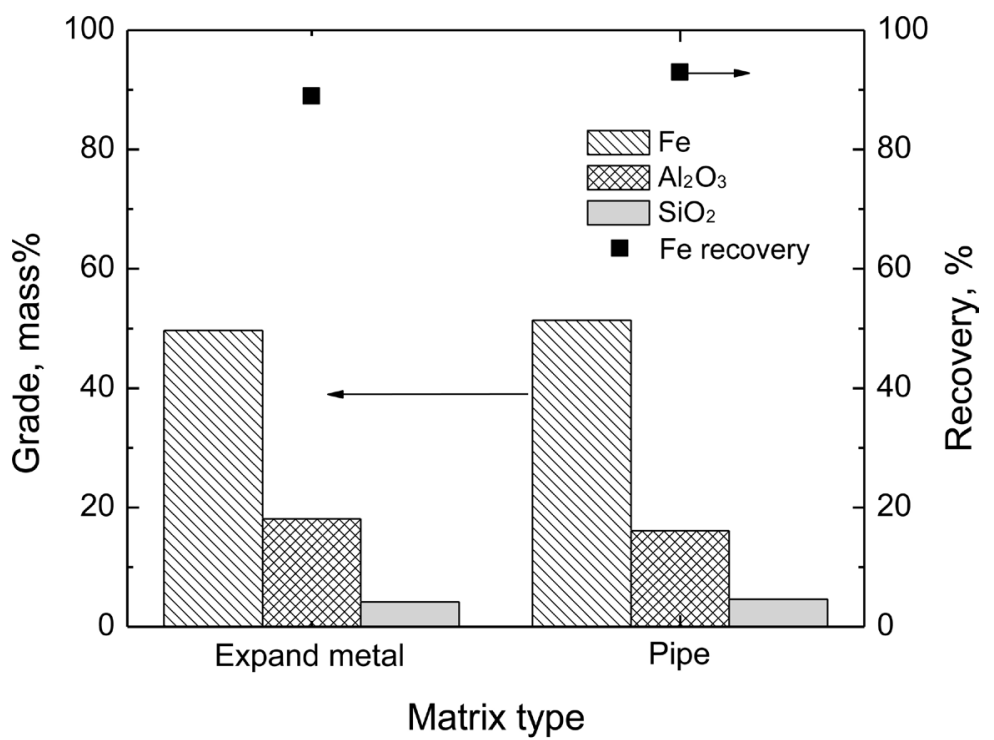

Figure 4. Changing of iron recovery and grade as a function of pulp density on WHIMS (conditions: magnetic density $10,000 \mathrm{mT}$, pulp flow rate $7 \mathrm{~L} / \mathrm{min}$, pulp density $2.5 \%$ ). 
the effect of matrix equipment. Iron with grade of 49.70 mass $\%$ and recovery of $89 \%$ was obtained for the expand metal while $93 \%$ was recovered using the pipe matrix. The iron grade also showed the higher content of 51.38 mass $\%$ when the pipe matrix was used as compared to the expand metal. This result shows that the pipe matrix has a simple structure compared with the expanded metal, hence the entrainment of silica and alumina was low and the iron minerals could be efficiently recovered.

\subsection{Reverse Flotation}

\subsubsection{Effect of Slurry $\mathrm{pH}$}

Figure 5 shows the effect of $\mathrm{pH}$ on the flotation of silica and alumina using DAA as cationic collector. Silica trend shows its lowest content of 31 mass\% in concentrate at $\mathrm{pH} 8$ and it was not removed with further increase in $\mathrm{pH}$. Iron grade trend shows a slight increase from $\mathrm{pH} 6.8$ to 8 . Further increase of $\mathrm{pH}$ from 8 to $\mathrm{pH} 10$ shows a relatively constant trend on Iron grade. The reaction mechanism of alumina and silica with amine collectors depends on the surface charge of the mineral particles [14]. The overall mineral surface charge in slurry strongly depends on the $\mathrm{pH}$ of the slurry [15]. When surface charge and the zeta potential of the hematite are more negative, the hydrophobicity of quartz increases. Increase in hydrophobicity of quartz during hematite flotation is attributed to more silicates attracted to cationic collectors and consequently increased silica-alumina recovery in the froth [16]. Recovery of Iron shows a constant trend also with an increase in $\mathrm{pH}$, this indicates that there was no direct dependence on $\mathrm{pH}$ for the flotation of silica and alumina using DAA collector alone.

\subsubsection{Effect of DAA Dosage}

The effect of DAA collector dosage on flotation of silica and alumina was

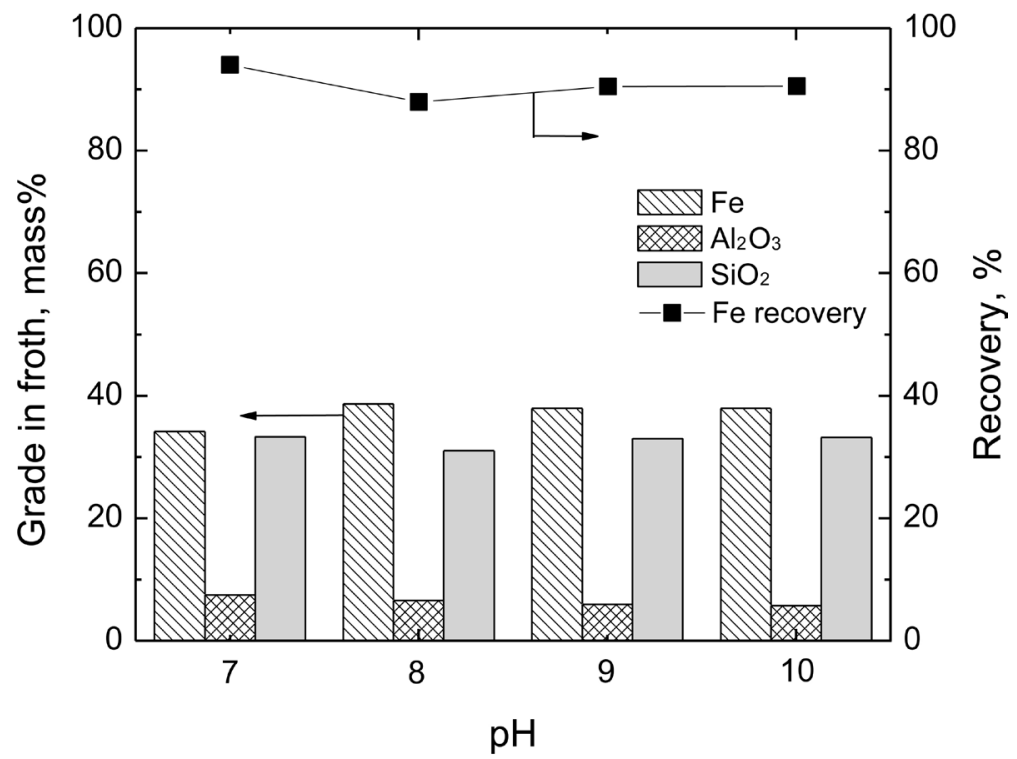

Figure 5. Changing of iron recovery and grade as a function of $\mathrm{pH}$ on reverse flotation (conditions: DAA addition $0.25 \mathrm{~kg} / \mathrm{t}$, MIBC $0.05 \mathrm{~kg} / \mathrm{t}$ ). 
investigated. The results in Figure 6 show that there was no iron recovered when $0.25 \mathrm{~kg} / \mathrm{t}$ of DAA collector was consumed. Increase in collector dosage from 0.50 $\mathrm{kg} / \mathrm{t}$ to $1 \mathrm{~kg} / \mathrm{t}$ using $0.1 \%$ DAA shows increase in iron recovery with over $76 \%$ iron recovered for $1 \mathrm{~kg} / \mathrm{t}$ DAA consumption. More alumina and silica was also removed as collector dosage was increased from 0.50 to $0.75 \mathrm{~kg} / \mathrm{t}$. Further addition of $0.1 \%$ DAA showed no further alumina reduction which implies that 0.75 $\mathrm{kg} / \mathrm{t}$ of $0.1 \%$ DAA was sufficient to allow the formation of a monolayer coat on alumina particles hence allowing it together with small silica bearing particles to report to the froth [17].

More floatation experiments were done using sodium oleate $(0.1 \% \mathrm{NaOL})$ collector in addition to DAA collector to improve the adsorption selectivity and consequently increase the ejection efficiency of silica and alumina [18].

Iron recovery shows an increasing trend with the addition of the $\mathrm{NaOL}$ as shown in Figure 7. The Iron recovery increased from $68.45 \%$ when DAA has used alone to $76.24 \%$ when the collector mixture of DAA and NaOL of 1:1 ratio was used. The suitable molar ratio was obtained at 1:2 which corresponds to the lowest silica content of 28 mass\%. Further addition of NaOL showed a relatively decreasing trend for both Iron grade and silica floatability.

\subsubsection{Effect of Starch Depressant}

To remove iron from floating together with silica and alumina, dextrin starch was used as a depressant. Additionally, $0.2 \mathrm{~kg} / \mathrm{t}$ of $\mathrm{CaO}$ was added as activator of $\mathrm{SiO}_{2}$. Figure 8 shows that iron grade increased with increase in starch dosage from 46.90 to 51.64 mass\%. More alumina was reduced at $1 \mathrm{~kg} / \mathrm{t}$ consumption with 2.90 mass\% remaining in the concentrate. Silica showed an improved reduction with increase in starch dosage with 20.60 mass\% content in the concentrate and considerably optimum starch dosage of $1 \mathrm{~kg} / \mathrm{t}$. On the other hands,

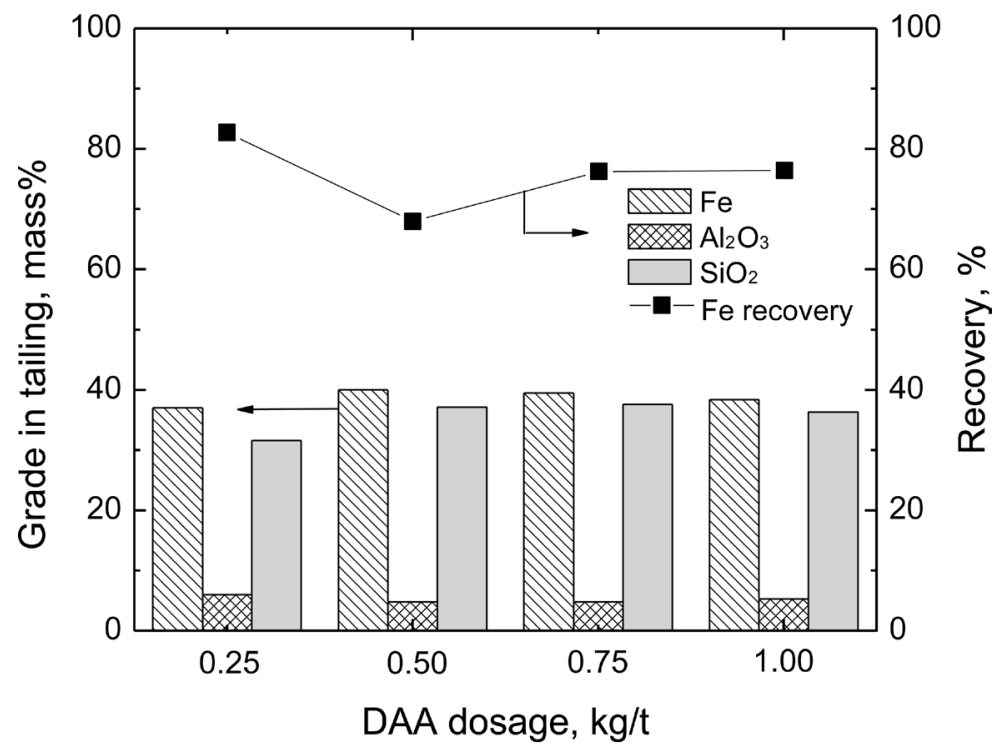

Figure 6. Changing of iron recovery and grade as a function of DAA dosage on reverse flotation (conditions: $\mathrm{pH} 8, \mathrm{MIBC} 0.05 \mathrm{~kg} / \mathrm{t}$ ). 


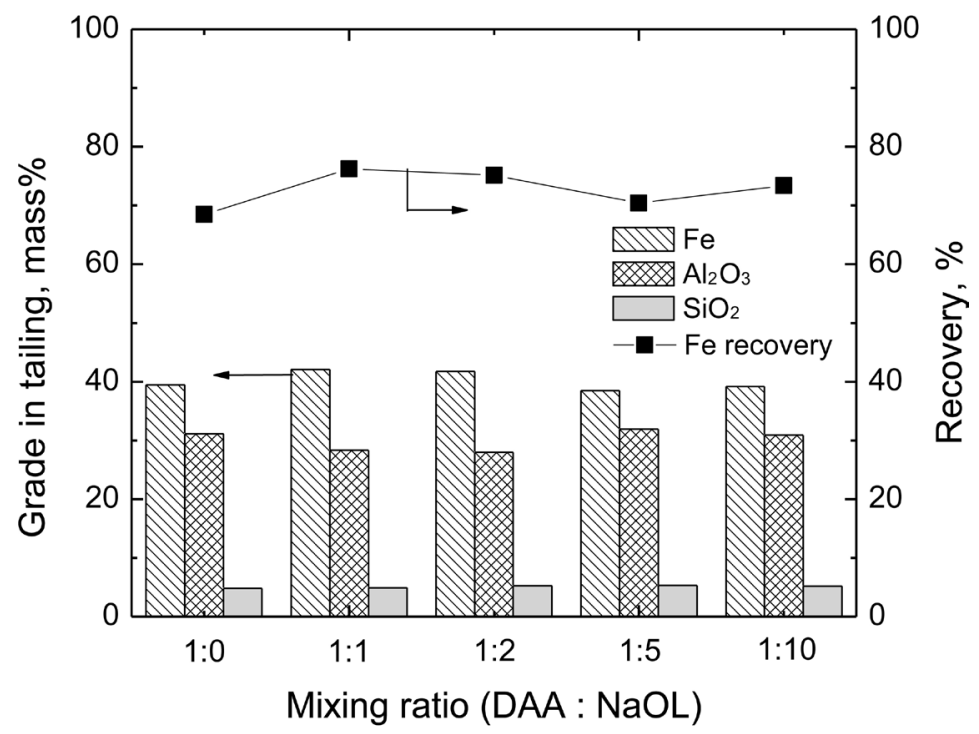

Figure 7. Effect of collector mixture on reverse flotation (conditions: DAA $0.75 \mathrm{~kg} / \mathrm{t}, \mathrm{pH}$ 8, MIBC $0.05 \mathrm{~kg} / \mathrm{t}$ ).

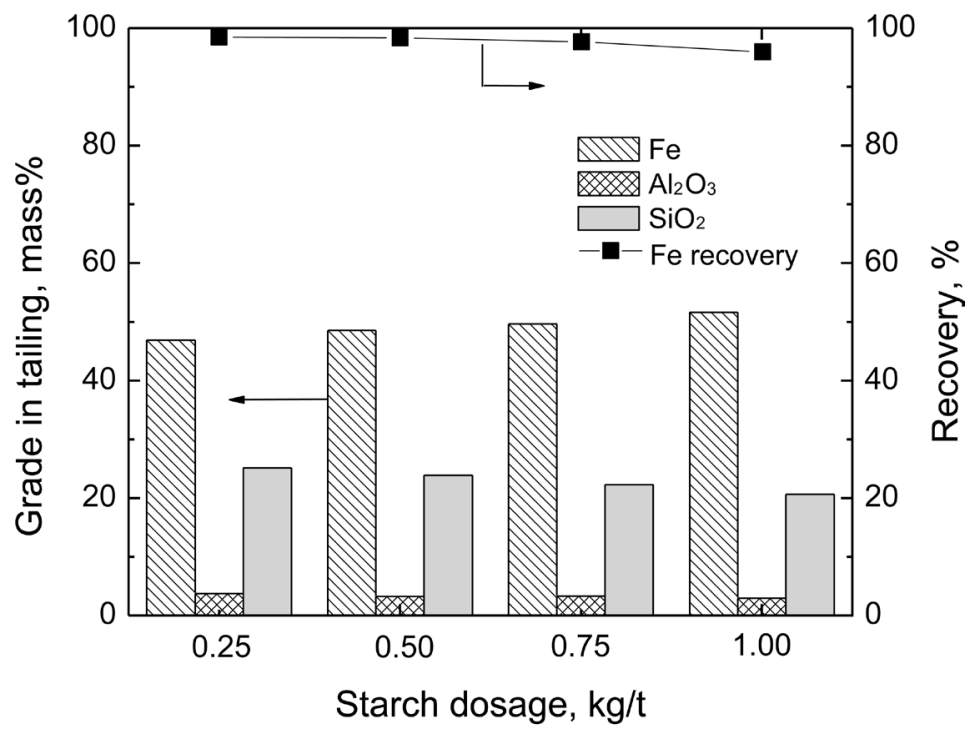

Figure 8. Effect of starch on flotation behavior of iron mineral, silica and almina (conditions: DAA $0.75 \mathrm{~kg} / \mathrm{t}, \mathrm{NaOL} 0.75 \mathrm{~kg} / \mathrm{t}, \mathrm{CaO} 0.2 \mathrm{~kg} / \mathrm{t}, \mathrm{MIBC} 0.05 \mathrm{~kg} / \mathrm{t}$ ).

iron recovery decreased from $98.46 \%$ to $95.95 \%$ with increased dosing from 0.25 to $1 \mathrm{~kg} / \mathrm{t}$. Similarly, Silica and alumina also were reduced with an increase in alkaline starch dosage to $20.60 \%$ and $2.90 \%$ respectively.

The improvement in both recovery and grade of iron as shown in Figure 8 indicates that starch was necessary to depress iron during flotation. The adsorption of starch on iron oxide was then investigated by infra-red analysis of the concentrate produced after starch dosing. Figure 9 shows FT-IR spectra of feed sample and starch added sample. The stretching vibration peak characterized at $1005 \mathrm{~cm}^{-1}$ indicating the Si-O bond indicating the presence of silicate [19]. After contact with starch, weak $\mathrm{CH}_{2}$ bonds were found and characterized by the small 


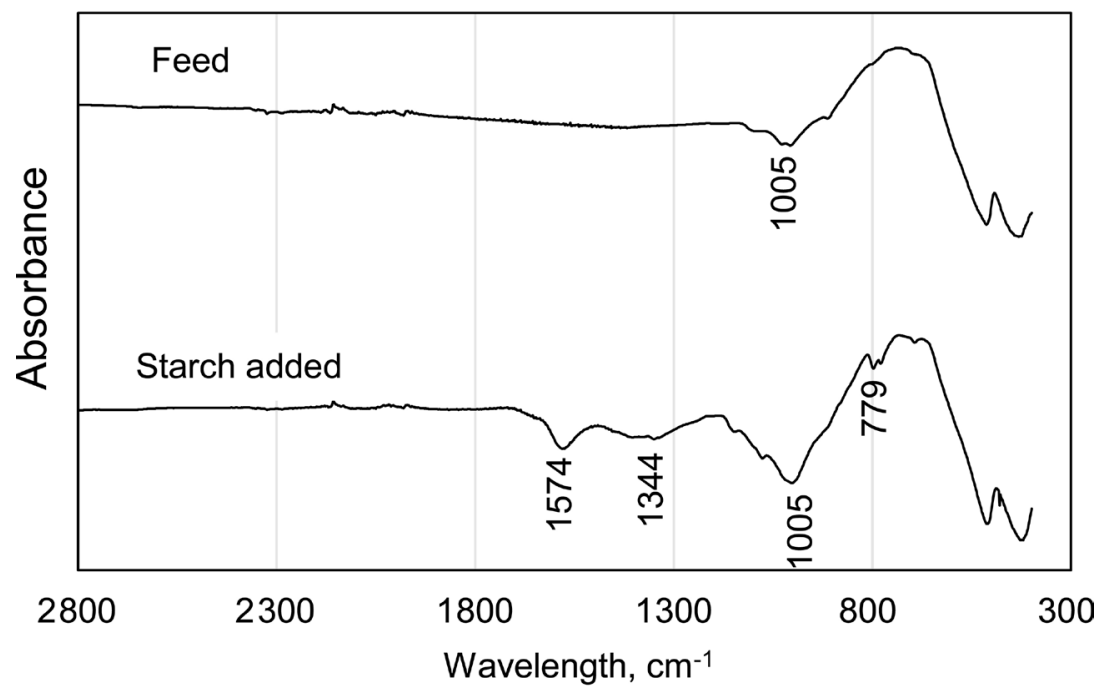

Figure 9. FT-IR spectra of feed sample and tailing obtained from flotation.

rocking vibration at $779 \mathrm{~cm}^{-1}$, a bending asymmetric peak of C-H bond at 1344 $\mathrm{cm}^{-1}$ and a small stretch at $1574 \mathrm{~cm}^{-1}$ characterizing the $\mathrm{CH}_{3}$ bond [20].

Adsorption of starch on hematite alters the surface charge of iron oxide to hydrophilic condition. Hydrophobicity of iron surface allows the iron oxide to settle as underflow and remain unattached to water bubbles floating silica and alumina. The adsorption of starch on iron particles was enhanced by the use of dodecyl amine acetate (DAA) as cationic surfactant for quartz-alumina particles. DAA was also used as a cationic collector whose interaction with silica-alumina particles resulted in the formation of a repulsive charge on iron bearing particles.

\subsection{Comparison of Combination Process of Magnetic Separation and Reverse Flotation}

Extraction of iron from Sanje ore by single stage magnetic separation or flotation process did not produce high grade iron concentrate with silica and alumina content. This is because Sanje ore has iron mineral particles which are strongly aggregated with silica and alumina and disintegration using single separation technique was difficult. As shown in Table 2, the second-stage magnetic separation processes was investigated using optimum conditions obtained from the first stage, namely, $10,000 \mathrm{mT}$ of magnetic field density, $2.5 \%$ pulp feed density, $25 \mu \mathrm{m}$ as feed particle density as suitable magnetic particle collection. Two-stage magnetic separation recovered $92.87 \%$ of iron with a grade of 67.07 mass $\%$ containing 1.30 mass\% of alumina and 2.14 mass\% silica. In the two-stage reverse flotation process, optimum conditions from the first stage process, such as collector dosage, starch dosage were also used in the second stage flotation. The combination process involving magnetic separation followed by reverse flotation involved using the concentrate from magnetic separation and optimum conditions from reverse flotation. The two-stage reverse flotation shows relatively lower iron grade of $55.53 \%$ with the lowest iron recovery of $87.65 \%$ with 2.60 
mass $\%$ of alumina and 15.80 mass $\%$ of silica containing in the concentrate. The flowchart of combination process of magnetic separation of reverse flotation shows in Figure 10. The magnetic separation followed by flotation process which recovered $89.50 \%$ of iron having a higher grade of 67.27 mass $\%$. Silica and alumina were reduced to 2.04 and 1.04 mass\% respectively. More alumina and silica were removed during magnetic separation followed by flotation process because the iron-silica and iron-alumina aggregated minerals were separated more by their difference in floatability [21] because there are weak magnetic particles and was difficult to separate them during two stage magnetic separation.

\section{Conclusions}

The mineral processing technique for effective removal of impurities from Sanje

Table 2. Composition of concentrates and iron recovery by two stage separation processes.

\begin{tabular}{ccccc}
\hline \multirow{2}{*}{ Combination process } & \multicolumn{2}{c}{ Iron concentrate, mass\% } & & $\%$ \\
\cline { 2 - 3 } & $\mathrm{Fe}$ & $\mathrm{Al}_{2} \mathrm{O}_{3}$ & $\mathrm{SiO}_{3}$ & $\mathrm{Fe}$ recovery \\
\hline $\begin{array}{c}\text { Magnetic separation-Magnetic separation } \\
\text { Reverse flotation-Reverse flotation }\end{array}$ & 67.07 & 1.30 & 2.14 & 92.87 \\
Magnetic separation-Reverse flotation & 55.53 & 2.60 & 15.80 & 87.65 \\
\hline
\end{tabular}

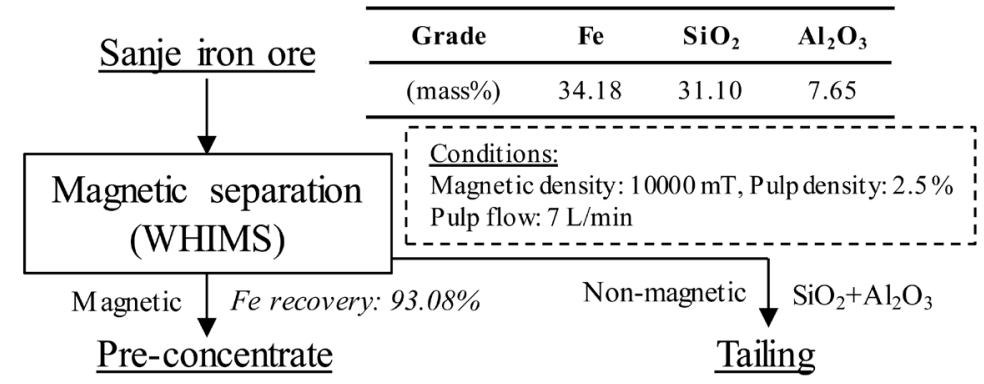

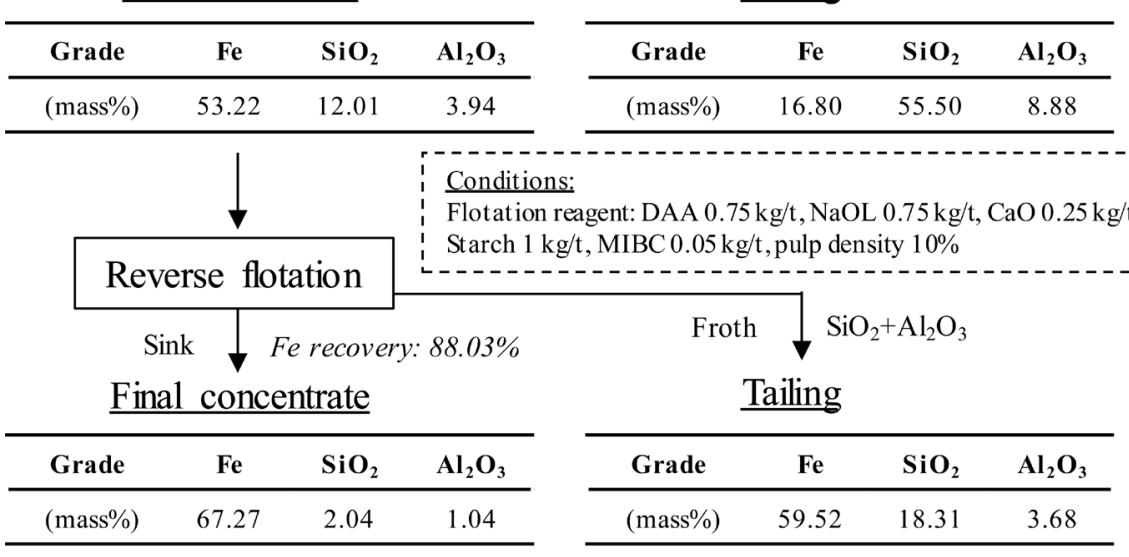

Total Fe recovery: $81.94 \%$

Figure 10. The proposed combination process of magnetic separation and reverse flotation for upgrading of low grade iron ore. 
Iron ore was established and therefore this study concludes that;

1) Effective removal of impurities from Sanje ore using wet high-intensity magnetic separation requires lower feed pulp density of $2.5 \%$ and higher magnetic field intensity of 10,000 mT. However, higher Iron grade with minimum impurities is not attained by single magnetic separation process with just up to 53.22 mass\% iron grade attained with 12.01 mass\% silica and 3.94 mass\% of alumina.

2) Reverse flotation using a mixture of cationic and anionic collectors (dodecyl amine acetate (DAA) and sodium oleate $(\mathrm{NaOL})$ ) shows a better silica-alumina gauge removal than when only DAA is used. However, it requires the use of starch as iron depressant.

3) A combined process of magnetic separation and reverse flotation is effective for removal of silica and alumina from Sanje ore. As proposed circuit, iron grade of obtained concentrate was 67.27 mass $\%$ and $81.94 \%$ of iron was recovered. Much of silica is reduced to $2.02 \%$ and alumina $1.04 \%$ remaining in the concentrate.

As a result of this research, a process to produce high quality iron concentrate from hematite based low-grade iron ore with high iron recovery rate was constructed. Impurities contained in iron ore include phosphorus and sulfur in addition to silica and alumina. It is necessary to investigate the process of processing low-grade iron ore considering these impurities in the future.

\section{Acknowledgements}

Acknowledgments and gratitude is hereby expressed to leading program of Akita University "New Frontier Leaders for Rare metal and Resources", Japan International Cooperation Agency (JICA), Japan International Cooperation Centre (JICE) and UMCIL Kafue Steel Plant.

\section{References}

[1] Ravelomanana, F., Yan, L., Mahazomanana, C. and Miarisoa, L. (2014) Modeling Africa's Demand for Iron and Steel Importation: An International Market Estimation Method Perspective. American Journal of Industrial and Business Management, 4, 799-815. https://doi.org/10.4236/ajibm.2014.412086

[2] Umadevi, T., Sah, R. and Mahapatra, P.C. (2014) Influence of Sinter Basicity $\left(\mathrm{CaO} / \mathrm{SiO}_{2}\right)$ on Low and High Alumina Iron Ore Sinter Quality. Mineral Processing and Extractive Metallurgy, Transactions of the Institutions of Mining and Metallurgy, 123, 75-85.

[3] Svoboda, J. (1994) The Effect of Magnetic Field Strength on the Efficiency of Magnetic Separation. Mineral Engineering, 7, 747-757.

https://doi.org/10.1016/0892-6875(94)90104-X

[4] Rath, S., Dhawan, N.D., Das, B. and Mishira, B.K. (2014) Optimal Recovery of Iron Values from a Low-Grade Iron Ore Using Reduction Roasting and Magnetic Separation, Separation Science and Technology, 49, 1927-1936. https://doi.org/10.1080/01496395.2014.903280

[5] Watson, J. (1994) Selectivity and Mechanical Retention in the Magnetic Separation 
of Polydisperse, Mixed Mineral Particle Systems. Minerals Engineering, 7, 769-791. https://doi.org/10.1016/0892-6875(94)90106-6

[6] Shao, T.J., Veasey, T.J. and Rowson, N.A. (1996) Wet High-Intensity Magnetic Separation of Iron Mineral. Magnetic and electrical Separation, 8, 41-51. https://doi.org/10.1155/1996/34321

[7] Rachappa, S. and Prakash, Y. (2015) Iron Ore Recovery from Low Grade by Using Advance Methods. Procedia Earth and Planetary Science, 11, 195-197. https://doi.org/10.1016/j.proeps.2015.06.024

[8] Araujo, A., Viana, P. and Peres, C. (2005) Reagents in Iron Ore Flotation. Minerals Engineering, 18, 219-224. https://doi.org/10.1016/j.mineng.2004.08.023

[9] Filippov, L.O., Severov, V.V. and Filippova, I.V. (2014) An Overview of the Beneficiation of Iron Ores via Reverse Cationic Flotation. International Journal of Mineral Processing, 127, 62-69. https://doi.org/10.1016/j.minpro.2014.01.002

[10] Ana, M.V. and Peres, A.E. (2007) The Effect of Amine Type, pH, and Size Range in the Flotation of Quartz. Minerals Engineering, 20, 1008-1013. https://doi.org/10.1016/j.mineng.2007.03.013

[11] Chen, L., Zeng, J., Guan, C., Zhang, H. and Yang, R. (2015) High Gradient Magnetic Separation in a Centrifugal Field. Minerals Engineering, 78, 122-127. https://doi.org/10.1016/j.mineng.2015.04.018

[12] Svoboda, J. and Ross, E. (1989) Particle Capture in the Matrix of Magnetic Separator. International Journal of Mineral Processing, 27, 75-94. https://doi.org/10.1016/0301-7516(89)90007-0

[13] Rachappa, S. and Prakash, Y. (2015) Iron Ore Recovery from Low Grade by Using Advance Methods. Procedia Earth and Planetary Science, 11, 195-197. https://doi.org/10.1016/j.proeps.2015.06.024

[14] Fuerstenau, D.W. (2005) Zeta Potentials in the Flotation of Oxide and Silicate Minerals. Advances in Colloid and Interface Science, 114-115, 9-26.

https://doi.org/10.1016/j.cis.2004.08.006

[15] Fouchee, A., Naude, N., Naik, S.K. and Schommarz, K. (2016) Optimization of Flotation $\mathrm{pH}$ for the Reverse Flotation of an African Low-Grade BIF Haematite Ore Journal of the Southern African Institute of Mining and Metallurgy, 116. https://doi.org/10.17159/2411-9717/2016/v116n12a4

[16] Liu, J.S., Laskowski, Y. and Wang, D. (2010) Effect of Dextrins on the Flotation Recovery of Molybdenite. Journal of Colloid and Interface Science, 346, 303-310.

[17] Filippov, L.O., Filippova, I.V. and Severov, V.V. (2010) The Use of Collectors Mixture in the Reverse Cationic Flotation of Magnetite Ore; The Role of Fe-Bearing Silicates. Minerals Engineering, 23, 91-98. https://doi.org/10.1016/j.mineng.2009.10.007

[18] Rao, K., Hanumantha, F. and Eric, A. (1990) Flotation of Mica Minerals and Selectivity between Muscovite and Biotite While Using Mixed Anionic/Cationic Collectors. Minerals \& Metallurgical Processing, 7, 127-132.

[19] Kou, J., Tao, D. and Xu, G. (2010) A Study of Adsorption of Dodecyl Amine on Quartz Surface Using Quartz Crystal Microbalance with Dissipation. Colloids and Surfaces A: Physicochemical and Engineering Aspects, 368, 75-83. https://doi.org/10.1016/j.colsurfa.2010.07.017

[20] Liu, W., Wei, D. and Cui, B. (2011) Collecting Performances of N-Dodecylethylene-Diamine and Its Adsorption Mechanism on Mineral Surface. Transactions of Nonferrous Metals Society of China, 1155-1160. 
https://doi.org/10.1016/S1003-6326(11)60836-4

[21] Dongfang, L., Yuehua, H., Yan, L., Tao, J., Wei, S. and Yuhua, W. (2017) Reverse Flotation of Ultrafine Magnetic Concentrate by Using Mixed Anionic/Cationic Collectors. Physicochemical Mineral Processing, 53, 724-736. 